\title{
$\widehat{A}$ Madridge \\ madridge Journal of Nursing \\ nterconn
}

Research Article

Open Access

\section{An Analysis of Peer Teaching between Adult Health and Nursing Assessment Students}

\author{
Kayla Hancock, Jessica Naber*, Summer Cross, and Tonia Mailow \\ School of Nursing and Health Professions, Murray State University, Murray, USA
}

\section{Article Info \\ *Corresponding author: \\ Jessica Naber \\ Assistant Professor \\ School of Nursing and Health Professions \\ Murray State University \\ Murray, USA \\ Tel: 502-541-3011 \\ E-mail:jnaber@murraystate.edu}

Received: February 18, 2016

Accepted: March 28, 2016

Published: April 4, 2016

Citation: Hancock KE, Naber JL, Cross S, Mailow TL. An Analysis of Peer Teaching between Adult Health and Nursing Assessment Students. Madridge J Nurs. 2016; 1(1): 1-6.

doi: $10.18689 / \mathrm{mjn}-1000101$

Copyright: @ 2016 The Author(s). This work is licensed under a Creative Commons Attribution 4.0 International License, which permits unrestricted use, distribution, and reproduction in any medium, provided the original work is properly cited.

Published by Madridge Publishers

\begin{abstract}
Peer-teaching is an educational strategy that has recently been incorporated into a School of Nursing curriculum. This change was analyzed to determine the effectiveness of peer-teaching from the nursing student perspective. The Adult Health II nursing students taught basic nursing skills to Nursing Assessment students, and a survey was anonymously completed by both the Adult Health II and Nursing Assessment students who voluntarily participated in the survey. The survey results were then used to analyze the successes and shortcomings of peer-teaching through comparison to findings from similar research projects. The aim of this research is to use the knowledge gained to influence future teaching strategies and classroom structure within Schools of Nursing. This research, therefore, illustrates the results of peer teachings and how those results will be used in the future nursing curriculum.
\end{abstract}

Keywords: Peer-teaching; Nursing student perspective; Nursing assessment; Student educator; Student learner.

\section{Introduction}

Background: Peer-teaching is a learning environment in which both the teacher and the student take on atypical roles. It is commonly referred to as the teaching style in which students are teaching students [1]. With this teaching style, more advanced students take on the role of being educators for less experienced students. Peer-teaching allows the advanced students to practice their teaching skills while reinforcing, and possibly relearning, past material. The newer students are still learning new material, but from a different teacher who is still a student and not yet an expert with practicing knowledge. To prepare for this type of teaching, the more advanced students develop a teaching plan covering previously learned nursing skills, and this material is then taught to the less experienced students. Although the actual professor does not teach the material, he or she has a vital role in reviewing the students' teaching plans and observing the peer-teaching.

The goal of this study was to introduce peer-teaching in the nursing laboratory setting and examine the nursing students' perspectives as found in survey results. In this particular study, the educator was an Adult Health II student who completed the Nursing Assessment course three semesters prior, and has since advanced to upper level nursing courses. The progression of knowledge prepares the upperclassmen to take on the role of an educator for the first semester nursing students. Peer-teaching also provides an opportunity for reinforcing basic nursing skills as the Adult Health II students prepare to take the NCLEX in the coming year. On the contrary, those being taught by the upperclassmen are first semester Nursing Assessment students who are learning the basic skills required for providing patient care in the hospital clinical settings. 


\section{Definitions}

Peer-teaching: A teaching experience where a more advanced student undertakes the role of an educator for the purpose of teaching an underclassman student who has a learning need and is, therefore, the learner.

Student educator: The more advanced student who is teaching. In this particular research, the Student Educator is the Adult Health II nursing student.

Student learner: The underclassman student who is learning from the teaching provided by the Student Educator. In this particular research, the Student Learner is the Nursing Assessment student.

\section{Purpose Statement}

The purpose of this study was to determine the peerteaching successes and shortcomings from the nursing student's perspective. Both the educator and the student learner's responses to the peer-teaching experience were used to gain a better understanding of the newly incorporated teaching style. The goal of this study was to ultimately determine whether the study results indicated student satisfaction and improved learning experiences, OR the need for continuation, termination, or changes to peer-teaching.

\section{Significance}

This research played a significant role in determining the peer-teaching successes and limitations from the nursing students' perspective. To gain a thorough understanding of the peer-teaching, a questionnaire was provided to the Adult Health II and Nursing Assessment students following the completion of peer-teaching. The anonymous questionnaire responses allowed for accurate data collection from the voluntary participants. The questionnaire results allowed the investigators to understand the new teaching style and its effect on student learning.

\section{Literature Review}

Within the literature, there are research articles written about the use of peer-teaching within various nursing programs and curriculum; however, only a few were published within the last five years. This lack of research within the last few years has created a significant knowledge gap in the area of peer-teaching within nursing programs. In order to understand the effects of this teaching style, data must be generated to examine the outcomes and necessary changes needed to improve peer-teaching.

One effect of peer-teaching, found within the literature, is the ability to enhance student and patient education [2]. The importance of providing patient education is a nursing role that is continually being emphasized, and peer-teaching is a method used to demonstrate the importance of teaching and learning from others [2]. As nursing students are being prepared to take on the role of competent nurses, it is important that they are equipped with the knowledge to teach patients about healthcare needs. It is even more important that the teaching is geared towards the learner's ability to understand, comprehend, and learn from the teacher's lesson. In order to gain a better understanding of both the educators' and the students' perspectives, peerteaching was incorporated into the nursing curriculum at a mid-size regional university and an evaluation was performed to analyze the results.

In addition to peer-teaching leading to nurses providing better patient education, it also allows the nursing students to become more confident when communicating and interacting with peers. A literature review of Kurtz, Lemly, and Alverson [3] indicated how peer-teaching has fostered leadership, reduced student anxiety, and facilitated the learning process. When the learning environment is improved for the students, the teaching experience will produce positive results. The authors illustrated this idea through the teaching strategy described as being one requiring student preparation, instructor review of the teaching plan, and delivery of the nursing skill in a professional manner. The authors found that peer-teaching allowed students to learn new material while experiencing an increase in confidence and competence [3].

Dennison [4] described a specific peer-teaching program. This program was referred to as a peer mentoring program, and it took place in a nursing laboratory setting within a southern Ontario university. The study took a closer look at senior nursing students who taught other nursing students within the laboratory setting. Prior to teaching fellow students, the peer mentors went through a hiring and orientation process. The benefits to the mentors included (1) an opportunity to review knowledge and skills, (2) networking with faculty, instructors and students, (3) participating in a rewarding experience by helping others, and (4) gaining respect of peers and faculty. The teaching experience also allowed mentors to reflect on how much they had learned and how much more they had to learn. In addition, the peer mentors were able to provide one-on-one attention to students in the learning environment. Benefits for the mentees who were taught by the student mentors included becoming less intimidated and more comfortable, and gaining perspective from a peer mentor who has had a similar experience [4].

Since student outcomes are of the utmost concern with peer-teaching, it is important to discuss the research that has shown mutual benefits for both the student educator and student learner. There are many benefits centered on improvement of nursing skills, but the educator and learner are also developing teaching and communication skills [5]. With the advancement in knowledge, the educator, who is an advanced nursing student, must adapt and present the lesson according to the knowledge level of the learner. Shortcomings, therefore, do exist if the peer-teachers are unprepared for the teaching session and provide inaccurate information to student learners [5]. The chance of providing inaccurate information, however, can be limited with the prior development of a teaching plan and the nursing professor's presence during the teaching session. 


\section{Methods}

Before the research study was conducted, approval was obtained from the Institutional Review Board (IRB) at the midsize regional university. The process of IRB approval consisted of the completion and submission of an application describing the research study and data collection methods. Also submitted was a questionnaire and cover letter that would be provided to the voluntary research participants. The questionnaire contained various questions related to the peer-teaching experience. A cover letter, attached to the front of the questionnaire, served as the participant's informed consent document. Information included on the cover letter included the title of the research study, the name of the primary investigator, and methods for contacting the investigator. Specific details about the research purpose, risks and benefits, and confidentiality of responses were also addressed. A statement describing risks was provided, and voluntary participation with protected confidentiality was emphasized. A copy of the questionnaire and cover letter accompanied the IRB application. Once IRB approval was obtained, the study was initiated under the supervision of the primary investigator.

The Adult Health II students prepared for the peerteaching by writing a formal teaching plan outlining the nursing skills to be taught to the Nursing Assessment students. The teaching plan was constructed by a group of approximately three students, and reviewed by the Adult Health II and Nursing Assessment professors. Each teaching plan described the learning needs of students followed by the goals, objectives, and content of the material to be taught. The teaching plan was concluded with rationales for teaching the specific nursing skill and an evaluation of the students learning response. Once the plan was reviewed by the Nursing Assessment professor, the peer-teaching was performed by the Adult Health II students.

The teaching session involved a setting that included cognitive and psychomotor learning. The Adult Health II students taught specific skills to the Nursing Assessment students, and the students then performed the skills under the supervision of the Adult Health II students. While the teaching was performed, the Nursing Assessment professor was present to provide additional insight into the teaching.

The student educator taught the following basic nursing interventions: vital signs, asepsis, hygiene, bowel and urinary elimination, activity and exercise, oxygenation and ventilation, circulatory support, diagnostic testing, and post mortem care. Once the teaching was completed by the student educators, the Nursing Assessment students divided into small groups and demonstrated the skills in a hands-on setting. This learning atmosphere allowed the student educators (Adult Health II students) and the Nursing Assessment professor to observe the student learners performing the skills and intervene if correction was needed.

Approximately halfway through the Fall 2015 semester, multiple peer-teaching sessions had been performed and an anonymous questionnaire was provided to the Nursing
Assessment students who had participated as learners in the peer-teaching experience. To maintain a consistent method of informing the Nursing Assessment and Adult Health II students about the purpose of the questionnaire, the primary investigator read a short statement to the students prior to the questionnaires being distributed. This statement described how peer-teaching was recently added to the curriculum at the mid-size regional university and research was being conducted to evaluate the effectiveness of the new teaching and learning style. The statement also included information about the questionnaire being conducted on a voluntary basis. Students were informed that the responses would remain anonymous and information provided would not be linked to participants. The questionnaire was provided at the end of the Nursing Assessment class by the primary investigator. Students who completed the questionnaire were asked to keep the cover letter for future questions that may arise pertaining to the research study. This same method was used when distributing the questionnaire to the Adult Health II students after the last peer-teaching session.

The questionnaire began by asking the participant to provide his or her age, gender, and current nursing semester. This information was necessary to analyze the research findings and organize the results. Following the unidentifiable personal information, the questionnaire contained a combination of Likert-scale, close-ended, and open-ended questions pertaining to the students' personal experience with peer-teaching. The importance of the questionnaire was the determination of the positive and/or negative outcomes of the teaching style; therefore, a comment section below each question provided students with the ability to freely discuss their thoughts.

\section{Results}

Results were gathered from 62 nursing students who completed the questionnaire. Thirty-nine students were from the Nursing Assessment class and were student learners in the peer-teaching experience. The remaining 23 students were Adult Health II students who were student educators for the Nursing Assessment students during the peer-teaching experience. The age of participants ranged from 19 to 30 with a mean score of 21.1 and a standard deviation of 2.08058 . Two students chose not to provide their age.

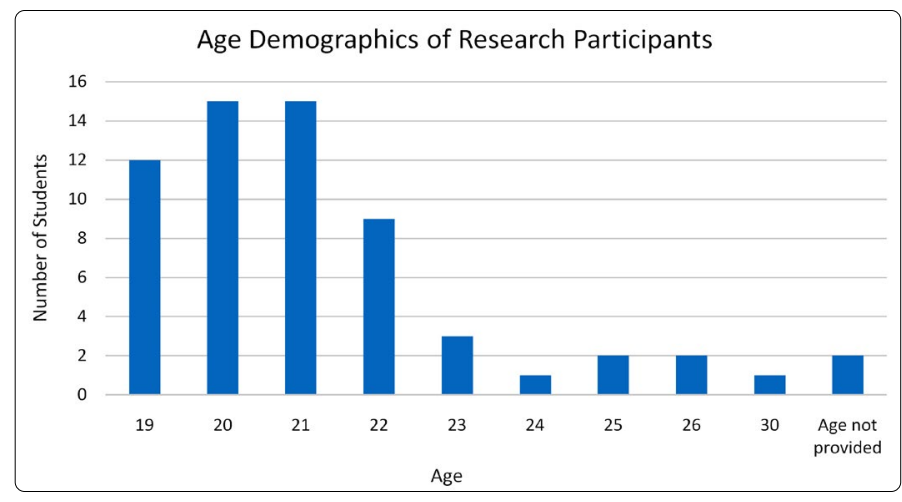

Figure 1. Age vs Number of students 
Out of the total number of questionnaires, 9 out of 62 (14.5\%) were completed by male nursing students and 52 out of $62(83.9 \%)$ were completed by female nursing students. One student chose not to provide his or her gender (1.6\%).

\section{Peer-teaching Experience}

The questionnaire began with a Likert-scale question that asked students to rate their experience with peer-teaching. The specific question asked, "How would you describe your experience with peer-teaching?" With a rating of 1 being negative and 10 being positive, the mean rating was 8.666 with a standard deviation of 1.199 . From those scores, $87.2 \%$ (34/39) of Nursing Assessment students reported a rating of 8 or higher with comments such as "[The Adult Health II students] did a good job at explaining the procedures, and they were good at allowing us to practice and making sure we understood [the nursing skill]" and "It is helpful to be taught by someone who understands what it is like to be in [the Nursing Assessment students] position."

Nursing Assessment students who gave a score of 7 or below reported the peer-teaching being different based on the Adult Health II students who taught the material. For example, one student wrote "Most times it's good, but last week I felt that [the Adult Health II students] didn't cover the material well." Another student expressed how peer-teaching was beneficial with some topics and not with others.

For the same question, the Adult Health II students rated peer-teaching with a mean score of 7.652 and a standard deviation of 1.695 . Approximately $60.9 \%$ (14/23) of Adult Health II students reported a score of 8 or higher. The student educators who had rated the peer-teaching experience as an 8 or above were accompanied by comments such as "I relearned important skills and was able to teach them too" and "It was a great refresher for us teaching, but an even better way for the [Nursing Assessment students] to learn. I wish we would've had this experience." From the Nursing Assessment student perspective, one student wrote "The older students have provided insight that our teachers do not usually provide. They are able to completely relate to us."The Assessment students often commented on how the advice from peer-teachers will positively impact their future clinical experiences, and the techniques they utilize when performing basic nursing skills in the hospital setting.

On the opposing side, 39\% (9/23) of Adult Health II students rated peer-teaching with a score of 7 or below with statements such as "It was time consuming so it took study time away from other classes to prepare for the teaching" and "The experience was fine but I did not feel like the [Nursing Assessment students] preferred us teaching." Another student educator wrote "the teaching itself was not difficult, but the knowledge of the presenting material could have been selftaught."

The same students who provided high ratings for the peer-teaching experience indicated specific benefits: handson, communication, effective learning/teaching, and relearning old skills. One student educator indicated that peer-teaching is beneficial because "hearing it from a student gives the younger classes a chance to hear it from a different perspective since it's someone who has just been through it recently." When comparing the previous response to a Nursing Assessment student's comment about the benefits of peer-teaching, the responses are very similar. This student wrote "the [Adult Health II] students were in our shoes just a short time ago. They gave insight and are able to answer all of our questions."

\section{Comprehension of Presentation}

The questionnaire also included a close-ended question asking if the lesson was presented in an easily understood manner. In addition to the "yes" or "no" response choices, a comment section below the question allowed students to write additional information pertaining to their answer choice. Out of all the responses, $97 \%$ of students (60/62) indicated that the peer-teaching material was taught in an easily understood way. Comments associated with this question included "If something wasn't understood, the students worked with us individually" and "[the student educators] put things into words more easily understood."

\section{Future Recommendations}

The questionnaire concluded with a close-ended question asking, "Would you like for more peer-teaching to be incorporated in future nursing courses?" The students were given a choice between "yes" and "no" followed by a section in which additional comments could be provided. Out of the 62 total questionnaires, $84 \%$ (52/62) of students indicated a desire to have peer-teaching in other courses and $16 \%$ expressed a desire to not have peer-teaching in other nursing courses. Students who were uninterested in having peerteaching in other nursing classes indicated how they would rather be taught by a professor. One student wrote, "As we progress through nursing school, we have less and less time to devote to sporadic teachings." A few other students also expressed how finding time for the peer-teaching was difficult because of other classes and clinical requirements.

\section{Suggested Changes}

While the questionnaire asked for student opinions of peer-teaching and its benefits, students were also asked to give suggestions of changes to make the teaching experience more successful. Since this is the first year of incorporating peer-teaching into the nursing curriculum at this mid-size regional university, a question was needed to analyze the current method and changes needed to improve the new teaching style. Five out of thirty-nine (almost 13\%) of Nursing Assessment students reported that the Adult Health II students needed "more preparation" prior to teaching. Other suggestions included providing handouts of the nursing skills, though the Nursing Assessment professor teaches with the Adult Health 2 students as assistants, and adding Adult Health II students to help with other nursing laboratory courses. The 
Adult Health II students had different suggestions for making the peer-teaching more successful. One student suggested "collaboration with the instructor on what [material] needs to be covered." Another student stated, "The things we taught were things that we hadn't even been taught yet." The Adult Health II students also suggested "more examples of the teaching plan and what is to be expected."

The questionnaire also asked participants about changes that could make the peer-teaching experience more successful. To this question, one student learner indicated the need to have students further along in the nursing program teach since some student educators were teaching skills they had yet to use. Other students indicated how handouts and short PowerPoints would be useful during the teaching sessions. Other suggestions included providing time for open question and answer, and including student educators in other nursing courses. While many suggestions were provided, some students indicated how no changes were needed to the new teaching style.

\section{Discussion}

When comparing the results from the questionnaires to results from previous research studies, similarities and differences are evident. Prihajo and Hoy [2] described enhanced student and patient education as a positive outcome of peer-teaching. Questionnaire responses, especially gathered from the Nursing Assessment students, indicated greater student learning when taught by the Adult Health II student. This was evident by a Nursing Assessment student stating, "We not only learn the material, but we hear clinical stories and can relate to these students." Another Nursing Assessment student wrote, "Both the [Nursing Assessment] and [Adult Health II] students benefit from peerteaching. The younger ones learn and the older ones have to know how to teach the material." An Adult Health II student indicated how peer-teaching "was a great refresher" that provided more "hands on experience" and "better skills."

Kurtz, et al. [3] indicated through their research that peerteaching fosters greater leadership skills and reduced student anxiety while facilitating the learning process. Students described satisfaction and increased confidence resulting from a leadership role in the peer-teaching experience. In addition, several Nursing Assessment students wrote how one benefit of peer-teaching is "being taught by someone who has been in our shoes." This comment was repeatedly seen throughout the Nursing Assessment students' questionnaires, and it indicates a decrease in anxiety resulting from peerteaching being taught by a more advanced student who had completed the course three semesters prior. One Nursing Assessment student clarified this point with the statement, "Students find it easier to hear information and stories from people closer to their age."

One recognizable difference between this peer-teaching experience and the one described by Dennison [4] is the process of obtaining student educators, or peer mentors as they are referred to in Dennison's literature. For this peerteaching experience, all the Adult Health II nursing students participated in the teaching whereas the peer mentors were chosen after a hiring and orientation process at the Southern Ontario University. The questionnaire responses indicated how the process could be improved to one that educates the advanced students on how to structure the peer-teaching sessions. This was evident through student responses specifying the need forbetter preparation prior to the teaching.

Dennison [4] also mentioned how peer-teaching allows peer mentors to recognize how much they had learned. This concept was evident through the Adult Health II nursing student's comment, "[Peer-teaching] gave me confidence that I've actually been learning stuff!" The peer-teaching experience provided an opportunity for the more advanced students to demonstrate their previously learned knowledge while teaching the skills to less experienced nursing students.

The mutual benefits of peer-teaching for the student learner and educator include teaching and communication skills [5]. A Nursing Assessment student indicated a positive peer-teaching experience through the response, "[The Adult Health II students] did a good job at explaining the procedures, and they were good at allowing us time to practice and making sure we understood [the material]." Communication skills were an important skill for the Adult Health II students to exhibit as they taught the less experienced students. The student educators had to be conscious of medical terminology and language that might be unfamiliar to the Nursing Assessment students. One student indicated this idea by writing, "We explained [the nursing skills] in a way that we thought they would understand it better. We used our own clinical experiences as well." This statement places further emphasis on the teaching and communication skills that were developed through the peer-teaching experience.

\section{Conclusion}

Peer-teaching has been a positive addition to the nursing curriculum at the mid-size regional university. The Nursing Assessment students benefitted from gaining insight and knowledge from the more advanced nursing students. Adult Health II students incorporated their learned knowledge into a teaching plan that was taught to the less experienced students. This enabled the students to teach the nursing skills in an easily understood manner.

Benefits of peer-teaching include increased student learning, review of previously learned skills, improved communication and teaching skills, and greater confidence. Areas of improvement for peer-teaching include better preparation for the teaching, more instructions on the teaching plan requirements, and providing additional materials to accompany the lesson presented.

Conflicts of Interest: The author(s) report(s) no conflicts of interest.

Consent: No consent is required to our article publication. 


\section{References}

1. Iwasiw $C$, Goldenberg D. Peer teaching among nursing students in the clinical area: Effects on student learning. J Adv Nurs. 1993; 18(4): 659668. doi: 10.1046/j.1365-2648.1993.18040659.x

2. Priharjo R, Hoy G. Use of peer teaching to enhance student and patient education. Nurs Stand. 2011; 25(20): 40-43.

3. Kurtz C, Lemley C, Alverson E. The master student presenter: Peer teaching in the simulation laboratory. Nurs Educ Perspect. 2010; 31(1): $38-40$.

4. Dennison S. Peer mentoring: Untapped potential. J Nurs Educ. 2010; 49(6): 340-342. doi: 10.3928/01484834-20100217-04

5. Williams B, McKenna L, French J, Dousek S. Measurement properties of a peer-teaching scale for nursing education. Nurs Health Sci. 2013; 15(3): 368-373. doi:10.1111/nhs. 12040 